\title{
OS SERVIÇOS AMBIENTAIS NA LEGISLAÇÃO FEDERAL E SUA COMPATIBILIDADE COM A ORDEM CONSTITUCIONAL BRASILEIRA
}

\author{
Carlos André Sousa Birnfeld \\ Marília Rezende Russo Correio
}

\section{RESUMO}

Abordando a problemática que envolve os serviços ambientais no contexto normativo federal brasileiro, o presente trabalho tem por objetivo investigar se o mesmo apresenta condições para viabilizar o adequado pagamento por serviços ambientais, em conformidade com os ditames constitucionais pertinentes. Trata-se de pesquisa exploratória, método de abordagem método indutivo e técnica de pesquisa bibliográfica. Inicia-se conceituando serviços ambientais e a seguir compila-se as bases constitucionais e principiológicas necessárias à compreensão da temática, culminando com análise da legislação federal e considerações sobre as Leis $\mathrm{n}^{\mathrm{o}} 12.114 / 2009,12.512 / 2011$ e 12.651/2012, com foco na sua compatibilidade com os cânones constitucionais antes fixados.

PALAVRAS-CHAVE: Serviços Ambientais; Constituição Federal; Pagamento por serviços ambientais; Princípio Poluidor-Pagador; Princípio Protetor-Recebedor.

\section{THE ENVIRONMENTAL SERVICES IN FEDERAL LEGISLATION AND ITS COMPATIBILITY WITH THE BRAZILIAN CONSTITUTIONAL ORDER}

\begin{abstract}
Addressing the problems that surround environmental services in the Brazilian federal normative context, the objective of this study is to investigate if it presents conditions to enable the adequate payment for environmental services, in accordance with the pertinent constitutional dictates. It is exploratory research, method of approach inductive method and technique of bibliographic research. It begins by conceptualizing environmental services and then compiles the constitutional and principological foundations necessary to understand the thematic, culminating with an analysis of the federal legislation and considerations on the Laws no. 12.144/2009, 12.512/2011 and 12.651/2012, focusing on its Compatibility with the previously established constitutional canons.
\end{abstract}


KEYWORDS: Environmental services; Federal Constitution; Payment for environmental services; Polluter-Paying Principle; Protector-Receiver Principle. 


\section{Introdução}

É fato notório o crescente comprometimento tanto do meio ambiente como dos recursos naturais que o compõem, em todo o planeta. Como resposta, os mais distintos ordenamentos jurídicos oscilam, de um lado, com respostas punitivas aos poluidores, muitas vezes incapazes de efetivamente restaurarem o dano ambiental já consolidado e de, outro, com medidas preventivas e precaucionais que são impostas, muitas vezes sem que haja fiscalização apta a verificar sua efetiva implementação.

Este é o contexto onde políticas de pagamentos por serviços ambientais (na verdade serviços humanos de favorecimento à manutenção em plenitude dos serviços ambientais) vêm sendo apontadas como uma opção viável para alcançar o objetivo de salvaguardar o meio ambiente e os recursos naturais, em conjunto com as demais políticas, pela qual, transcendendo meras imposições de obrigações de fazer ou não fazer, se tem o estímulo positivo às condutas proativamente favoráveis ao meio ambiente.

Não se trata, todavia, de horizonte de fácil tratamento, pois que é preciso ter claro quais condutas, não meramente coincidentes com o dever legal de preservação, devem ser estimuladas, a que custo e por quem financiadas e, fundamentalmente, em que marcos regulatórios estas atividades encontrar-se-ão situadas, o que efetivamente não se encontra consolidado no horizonte doutrinário pátrio, em que pese a crucial importância do instituto para a questão ambiental. Por tudo isso justifica-se a opção por esta pesquisa, que buscará investigar justamente o quanto o ordenamento jurídico federal pátrio apresenta efetivo potencial para viabilizar o pagamento por serviços ambientais, dentro dos cânones constitucionais postos.

Assim, o presente trabalho terá por foco responder a seguinte indagação: a legislação federal brasileira apresenta condições para viabilizar o adequado pagamento por serviços ambientais, em conformidade com os ditames constitucionais e principiológicos sobre o tema?

Quanto ao método, destaca-se o fato de se tratar de pesquisa exploratória, conveniente para o relato de fenômenos recentes, cujo assentamento doutrinário e mesmo jurisprudencial é de fato escasso. Neste sentido, o método de abordagem será o método indutivo, pelo qual as particularidades encontradas nos universos observados - no caso as normas federais - serão utilizadas para a construção da pertinente compilação. A técnica de 
pesquisa utilizada será a bibliográfica, com especial atenção aos textos normativos da legislação federal e a doutrina necessária à elucidação das variáveis envolvidas.

Nesta perspectiva iniciar-se-á o trabalho aprofundando-se o conceito de serviços ambientais, procurando esclarecer no que efetivamente consistem, ingressando, a seguir, na conceituação do pagamento pelos serviços ambientais. No segundo tópico avançar-se-á nas bases normativas que devem servir de norte para a temática do pagamento pelos serviços ambientais, com foco especial na Constituição e nos princípios atinentes à matéria, com vistas a construir um conceito normativo apto a medir a efetiva adequação das normas federais de pagamento por serviços ambientais à ordem constitucional. O terceiro e último tópico envolverá uma apresentação reflexiva da legislação federal vigente no Brasil sobre os próprios serviços ambientais, tendo por foco, na sequência, a breve análise das três normas federais vigentes sobre o tema: a Lei $\mathrm{n}^{\circ} 12.114 / 2009$, que cria o Fundo Nacional sobre Mudança de Clima; a Lei $\mathrm{n}^{\circ}$ 12.512/2011, que cria o Programa Bolsa Verde e a Lei $\mathrm{n}^{\circ}$ 12.651/2012, que institui o novo Código Florestal, trazendo-se ao final, as pertinentes considerações sobre o enquadramento das mesmas nos cânones constitucionais fixados no tópico anterior.

\section{Delimitando o Conceito de Serviços Ambientais}

Para fins do presente opúsculo, se faz necessário aprofundar minimamente algumas questões: o que são serviços ambientais, quem (ou o quê) efetivamente o presta estes serviços para quem (ou o quê), quem efetivamente deve pagar por isso e como poderá pagar?

Neste sentido é preciso delimitar desde já que o conceito de serviço ambiental abrange essencialmente serviços que são fornecidos, prestados, a priori, pela própria natureza. Trata-se, em essência, de riquezas fornecidas pela própria natureza, compreendidas estas no conceito de Renato Cordeiro ${ }^{1}$ como "os bens, os serviços e o quadro natural de que podem

1 Renato Caporali Cordeiro, que foi orientando dileto de Ignacy Sachs, desenvolve brilhante tese de doutoramento, sintetizada na obra Da Riqueza das Nações à Ciência das Riquezas, demonstrando que a Ciência Econômica é profundamente limitada para as questões ambientais, justamente porque opera a partir do conceito de valor, medido pela escassez, que distingue-se do conceito de riqueza, a ser medido por uma possível Ciência das Riquezas, que envolveria uma teoria da produção e gestão visando abundância social de recursos (CORDEIRO, 1995, p. 182), destacando, na comparação, "que estamos na presença de duas estruturas cujo estatuto epistemológico não é idêntico, e que sua relação é algo de complexo numa sociedade regulada pelo mercado" (CORDEIRO, 1995, p. 110). Nesta perspectiva, resgata os clássicos da economia, como Ricardo, que explica que "a riqueza de uma nação não se mede pela abundância de seu numerário, ou pelo alto preço pecuniário de suas mercadorias, mas pela abundância de objetos que contribuem ao seu bem-estar e seus prazeres (CORDEIRO, 1995, p. 125) e Alfred Marshal, para quem "o Tâmisa acrescentou riqueza à Inglaterra mais do que todos os seus canais e talvez mesmo que todas as suas estradas de ferro (CORDEIRO, 1995, p. 27).

Revista de Direito Ambiental e Socioambientalismo | e-ISSN: 2525-9628 | Brasília | v. 3 | n. 1 | p. 18 - 39 | Jan/Jun. 2017. 
usufruir os homens privadamente e em sociedade" (1995, p. 1). Neste sentido, este autor, ao comentar as distinções entre valor e riqueza de David Ricardo, ponderou "o rio pode contribuir muito para a riqueza precisamente porque ele não tem valor: ele não é escasso e não tem, ou melhor, não tinha, hoje tem - custo de produção. Quanto mais puder contribuir à riqueza social sem se tornar valor, tanto melhor." (CORDEIRO, 1995, p. 27) (grifos nossos)

Chama atenção, para a questão dos serviços ambientais, exatamente a perspectiva de Cordeiro sobre o Tâmisa: esse rio pode muito contribuir para riqueza - ou seja, prestar serviços ambientais - ainda que não tivesse outrora custo de produção, que hoje existe - ou seja, hoje seriam necessários esforços adicionais humanos para que o Tâmisa pudesse prestar adequadamente os seus serviços ambientais. Esse é o exato contexto em que se situa a questão dos serviços ambientais.

Neste sentido - e já trazendo a questão para os rios brasileiros - Henry Phillippe Ibanes de Novion exemplifica os serviços ambientais fluviais:

Os rios ao secar, transportam cada vez menos nutrientes, empobrecendo os solos. Todas essas alterações no bom funcionamento dos serviços da natureza (chuva, polinização, fertilização de solos), prejudicam todos que da natureza dependem, como por exemplo, os que plantam alimentos. A essa ajuda da natureza, de que todos dependemos, dá-se o nome de serviço ambiental. (2010)

Nesta perspectiva, há doutrinadores que denominam os benefícios gerados pelo meio ambiente como serviços ambientais, mas há os que trazem o conceito de serviços ecossistêmicos, de forma que a distinguir os serviços prestados pelos humanos ao meio ambiente e vice-versa. Para Fernando Cesar da Veiga Neto e Peter H. May:

Há certa confusão na literatura entre os conceitos de "serviços ambientais" e "serviços ecossistêmicos". Serviços ecossistêmicos foram definidos por Dailey (1997) como os serviços prestados pelos ecossistemas naturais e as espécies que os compõem, na sustentação e preenchimento das condições para a permanência da vida humana na Terra. Serviços ambientais são mais relacionados com os resultados desses processos, ou ainda quando se deseja atrelar as ações antrópicas associadas à restauração e manutenção dos serviços ecossistêmicos, enquanto as funções dos ecossistemas são mais associadas com a sua origem. [...] (2010, p. 310).

No mesmo sentido as autoras Susan Edda Seehusen e Ingrid Prem enunciam que há diversas definições para serviços ecossistêmicos e serviços ambientais, sendo que no estudo "Por que pagamentos por serviços ambientais?" (2012) optaram por usar a terminologia de serviços ambientais, considerando que esses compreendem tanto os serviços proporcionados

Para Cordeiro, a lógica da riqueza obedece a princípios relativos de organização social do processo do trabalho e à capacidade técnico-energética de transformação da natureza (1995, p. 182). Neste particular, riqueza distinguese de valor e de sua expressão política, a moeda, o meio monetário. Nos termos de Cordeiro "para o indivíduo, a moeda pode transformar-se em riqueza, desde que ela exista" (1995, p. 23), não deixando nunca de ser mero indicador de uma dívida da sociedade para com seus detentores (Ibidem, p. 23).

Revista de Direito Ambiental e Socioambientalismo | e-ISSN: 2525-9628 | Brasília | v. 3 | n. 1 | p. 18 - 39 | Jan/Jun. 2017. 
ao ser humano por ecossistemas naturais (os serviços ecossistêmicos), quanto os providos por ecossistemas manejados ativamente pelo homem. Como exemplo, relatam que o homem pode induzir positivamente a oferta de serviços ambientais a partir da sua escolha em empregar práticas agrícolas diversificadas e sustentáveis em uma área em detrimento de atividades potencialmente degradantes.

Com a devida vênia, o fato é que, afora sua modesta participação nos ciclos da natureza, a humanidade não presta sozinha, como regra, nenhum serviço ambiental relevante, sequer para sua própria espécie. Neste sentido, para fins conceituais, especialmente desta pesquisa, não há que se falar em serviços ambientais abrangendo, de alguma forma, serviços prestados pelo homem, posto que é inevitável reconhecer que os serviços em questão efetivamente são aqueles prestados pela própria natureza, em que pese se deva ter claro também que a expressão serviços tenha sido historicamente designada para descrever atividades humanas colocadas no mercado.

Seja como for, a própria identificação das atividades da natureza como serviços, constitui corolário de um contexto de emergência de novos tempos, nos termos relatados por Birnfeld, o tempo da "Cidadania Ecológica" (2006) e o tempo em que já se noticia o reconhecimento constitucional da natureza como sujeito de direitos ${ }^{2}$. Neste contexto, não há porque antropologizar os serviços ambientais. Deixe-se ao homem - e às mulheres - o eventual mérito do auxílio ao regular desenvolvimento dos serviços ambientais ou, como querem alguns, dos serviços ecossistêmicos, os quais, sob quaisquer denominações, continuam sendo aqueles prestados pela natureza, pelo menos para o escopo do presente trabalho.

Estabelecidas estas bases iniciais, convém aprofundar minimamente o conteúdo efetivo dos serviços prestados pelo meio ambiente: no contexto da ONU, a Avaliação Ecossistêmica do Milênio (ALCAMO, et al., 2003) define os serviços ecossistêmicos como os benefícios que as pessoas obtêm dos ecossistemas, sendo que entre eles incluem-se serviços de provisões como alimentos e água, serviços de regulação como controle de enchentes e de pragas, serviços de suporte como o ciclo de nutrientes que mantém as condições de vida na Terra, e serviços culturais como espirituais, recreativos e benefícios culturais. Neste contexto, os serviços ambientais podem ser classificados da seguinte forma (ALCAMO, et al., 2003):

a) Serviços de Suporte (serviços necessários para produção de todos os outros

2 Como é o caso explícito da Constituição do Equador de 2008, em seu Art. 71, ou implícito. 
serviços ecossistêmicos):

a.1.) Formação do Solo;

a.2.) Ciclos de Nutrientes;

a.3.) Produção Primária.

b) Serviços de Provisão (produtos obtidos dos ecossistemas):

b.1.) Alimentos;

b.2.) Água Potável;

b.3.) Combustível;

b.4.) Fibras;

b.5.) Compostos Bioquímicos;

b.6.) Recursos Genéticos.

c) Serviços de Regulação (benefícios obtidos através da regulação dos processos dos ecossistemas):

c.1.) Regulação do Clima;

c.2.) Regulação de Doenças;

c.3.) Regulação da Água;

c.4.) Purificação da Água.

d) Serviços Culturais (benefícios não materiais obtidos dos ecossistemas):

d.1.) Espirituais e religiosos;

d.2.) Recreio e turismo;

d.3.) Estéticos;

d.4.) Inspiradores;

d.5.) Educacionais;

d.6.) Sensação de lugar;

d.7.) Herança cultural.

Considerando os conceitos e a classificação dos serviços ambientais acima apresentados, verifica-se que os benefícios gerados por esses serviços proporcionam as condições e os processos que dão suporte à vida e, de maneira direta ou indireta, contribuem para a sobrevivência e o bem-estar humano tanto nas comunidades urbanas como rurais.

No mesmo compasso, oportuno mencionar os exemplos de serviços ambientais providos especificamente por florestas tropicais (SEEHUSEN; PREM, 2012):

a) BIODIVERSIDADE: proporciona como benefícios para a sociedade, por exemplo, a madeira, as folhas, os frutos e as sementes das plantas que podem servir como medicamentos, alimentos, matérias-primas para a fabricação de móveis, para construção de casas, entre outros. Também possibilita serviços de polinização e garante a resiliência de sistemas agrícolas. Além disso, a biodiversidade contribui para a formação dos solos e para a ciclagem de nutrientes. 
b) ARMAZENAMENTO E SEQUESTRO DE CARBONO: as plantas absorvem carbono através da fotossíntese do dióxido de carbono atmosférico. Nas florestas em crescimento, o montante de carbono sequestrado aumenta, estabilizando quando elas chegam à maturidade.

c) SERVIÇOS HIRDOLÓGICOS: florestas influenciam os processos hidrológicos, como a regulação dos fluxos hídricos e a manutenção da qualidade da água. Preservando-se florestas em margens de rios, encostas e topos de morros e montanhas reduzem os riscos de inundações e deslizamentos por extremos climáticos.

d) BELEZA CÊNICA: as belas paisagens formadas pelo grupamento entre florestas, rios, cachoeiras, montanhas e praias, agregadas à mistura de populações e culturas, fazem das florestas tropicais algo especial. Além disso, o lazer, a recreação e a inspiração dotada por esses ecossistemas beneficiam não só as populações locais, mas as de grandes centros urbanos, inclusive turistas internacionais.

e) SERVIÇOS CULTURAIS: os ecossistemas e as espécies ofertam serviços culturais para a sociedade ao satisfazer suas necessidades espirituais, psicológicas e estéticas. Neste contexto, salienta-se as populações rurais e particularmente as tradicionais, como caiçaras, indígenas, quilombolas e caboclos, as quais têm sua cultura, crenças e modo de vida relacionados aos serviços culturais de ecossistemas nativos.

Nesta perspectiva, é possível definir serviços ambientais como atividades, produtos e processos essenciais que a natureza fornece e que possibilitam a manutenção da vida como um todo, especialmente a vida humana e para os quais a colaboração humana pode revelar-se eventualmente facilitadora para seu desenvolvimento e manutenção.

É neste contexto que se há de observar o instrumento jurídico-econômico objeto do presente estudo, o qual vem sendo visto como uma alternativa para que o ser humano adote práticas conservacionistas de manejo de recursos naturais, qual seja o pagamento por serviços ambientais. O mesmo é definido por Sven Wunder como:

1. uma transação voluntária na qual

2. um serviço ambiental bem definido ou uma forma de uso da terra que possa assegurar este serviço

3. é comprado por pelo menos um comprador

4. de pelo menos um provedor

5. sob a condição de que o provedor garanta a provisão deste serviço. (apud WUNDER, et al, 2009).

Destarte, para o adimplemento de serviços ambientais pelo menos quatro condições devem ocorrer, quais sejam:

1. Serviço ambiental definido: a existência de um serviço ambiental muito bem definido cuja manutenção e/ou suprimento seja de interesse para alguém. Este será o "produto" a ser comercializado. 
2. Pagador/Comprador: pessoa física ou jurídica tem que estar disposto a pagar por este "produto", no caso, para a conservação e/ou recuperação do serviço ambiental.

3. Recebedor: pessoa física ou jurídica que recebe um recurso financeiro e em troca deve se comprometer a manter e/ou recuperar este serviço ambiental.

4. Voluntariedade: a transação de pagar e receber por um serviço ambiental deve ser antes de tudo voluntária, isto é, os envolvidos na transação devem participar porque querem e não por obrigação. (TITO; ORTIZ, 2013).

Diante da definição exposta, tratando-se de um bem ambiental "muito bem definido", verifica-se a dificuldade na operacionalização, uma vez que boa parte dos serviços ocorre a partir de um significativo complexo de interações, o que dificulta tanto a mensuração do serviço como a participação dos sujeitos, inclusive no que tange às respectivas mensurações de comprometimento.

No que tange aos sujeitos, identifica-se como "pagador/comprador" de um serviço ambiental qualquer pessoa física ou jurídica, privada ou pública que queira custear o mesmo. Quanto ao "recebedor/provedor" é aquela pessoa física ou jurídica que atua para favorecer a preservação e o desenvolvimento dos recursos naturais relacionados ao serviço ambiental. Entre os sujeitos, a perspectiva de uma transação financeira voluntária, a qual, evidentemente deve ser relativizada: não se pode esperar, no contexto capitalista, um comprador que esteja a aderir voluntariamente ao pagamento sem que o interesse voluntário no pagamento pelo serviço não decorra de outro interesse, notadamente o interesse em cumprir algum tipo de obrigação ambiental. E de outra banda, não se pode pretender que o recebedor deixe de ter interesse financeiro, além do próprio interesse ambiental eventualmente envolvido.

Dito isso, é possível analisar as bases jurídicas que hão de nortear este contexto.

\section{Fundamentos de ordem constitucional e principiológica necessários ao balizamento da legislação referente ao pagamento pelos serviços ambientais}

A Constituição Federal de 1988 em seu artigo 225 reconheceu a importância do meio ambiente para o bem-estar humano ao prever que:

Todos têm direito ao meio ambiente ecologicamente equilibrado, bem de uso comum do povo e essencial à sadia qualidade de vida, impondo-se ao Poder Público e à coletividade o dever de defendê-lo e preservá- lo para as presentes e futuras gerações. (grifos nossos)

No $\$ 3^{\circ}$ do mesmo artigo, revela-se explicita a obrigação ambiental (pública e privada) "de reparar os danos causados" por "condutas e atividades consideradas lesivas ao meio ambiente", os quais sujeitam-se a sanções penais e administrativas, constituindo-se, 
outrossim, obrigação do Poder Público, nos termos do $\S 1^{\circ}$, inciso IV, do mesmo artigo, “exigir, na forma da lei, para instalação de obra ou atividade potencialmente causadora de significativa degradação do meio ambiente, estudo prévio de impacto ambiental".

Neste sentido, se observa que o dever de proteção ambiental - e com ele de proteção aos correlatos serviços ambientais - se apresenta cristalino na ordem constitucional, inclusive com desdobramentos no campo da precaução, prevenção e reparação. Além disso, no que tange especificamente ao Poder Público, Birnfeld (2003) cita praticamente uma dezena de deveres ambientais explícitos determinados ao Poder Público em matéria ambiental, abrangendo os mais distintos recursos naturais e culturais ${ }^{3}$. Estas perspectivas, juntamente com outras, levam o mesmo autor a afirmar, em sua tese de doutoramento, que:

o princípio poluidor-pagador encontrando-se implícito na ordem constitucional brasileira, tem como consequência a imputação efetiva ao poluidor de todos os encargos decorrentes de sua atividade poluente, imputação esta que só é possível de ser concebida em plenitude na medida em que, na sua hermenêutica e aplicação, sejam transcendidas as suas inadequadas referências estritamente economicistas, relacionadas com a mera conversão da dilapidação das riquezas ambientais em recursos monetários. (BIRNFELD, 2003, p. 388)

Para este autor a ordem constitucional consagra implicitamente o princípio poluidorpagador, cujo conteúdo envolve a imputação efetiva ao poluidor de todos os encargos decorrentes da sua atividade poluente, de forma que não persista a sociedade como um todo, presente ou futura, onerada pela ação poluidora de apenas um de seus membros (BIRNFELD, 2003, p. 388), encargos estes que abrangem tanto os deveres de precaução, prevenção como de reparação imediata em relação à qualquer lesão ao fornecedor de serviços ambientais. Nesta perspectiva, justo porque procura encarregar o próprio poluidor dos encargos de preservação relacionados às suas atividades, reservando ao Poder Público dos demais, nos termos do $\S 1^{\circ}$ do Art. 225, a Constituição não estabelece, em nenhum momento, qualquer tipo de previsão de pagamento pelas obrigações de fazer ou não fazer relacionadas à preservação ambiental, das quais, em essência, decorre a própria manutenção dos serviços ambientais.

Neste contexto, em que sentido é possível que a legislação infraconstitucional

3 Entre os quais preservar e restaurar os processos ecológicos essenciais e prover o manejo ecológico das espécies e ecossistemas; preservar a diversidade e a integridade do patrimônio genético do País; promover a educação ambiental em todos os níveis de ensino e a conscientização pública para a preservação do meio ambiente; preservar as florestas, a fauna e a flora; proteger os documentos, as obras e outros bens de valor histórico, artístico e cultural, os monumentos, as paisagens naturais notáveis e os sítios arqueológicos; promover e proteger o patrimônio cultural brasileiro, por meio de inventários, registros, vigilância, tombamento e desapropriação, e de outras formas de acautelamento e preservação; impedir a evasão, a destruição e a descaracterização de obras de arte e de outros bens de valor histórico, artístico ou cultural; preservar as florestas, a fauna e a flora (BIRNFELD, 2003, p. 162-163).

Revista de Direito Ambiental e Socioambientalismo | e-ISSN: 2525-9628 | Brasília | v. 3 | n. 1 | p. 18 - 39 | Jan/Jun. 2017. 
brasileira possa abarcar o pagamento aos agentes que preservem o meio ambiente para a manutenção dos serviços ambientais, se, a priori, todos tem o dever de preservá-la - e, portanto, não fariam mais do que sua obrigação?

Antes de enfrentar diretamente esta questão convém examinar, ainda que brevemente, o princípio que orienta o pagamento pelos serviços ambientais.

\subsection{O Princípio do Protetor-Recebedor}

O Princípio do Protetor-recebedor não se encontra, de fato, nem explícita, nem implicitamente na ordem constitucional, sendo que sua âncora constitucional mais próxima, ainda que eventualmente tangencial, pode estar relacionada ao princípio do tratamento econômico diferenciado conforme o impacto ambiental dos produtos e serviços e de seus processos de elaboração e prestação, insculpido no Art. 170, VI, que abre portas para políticas públicas de fomento a atividades produtivas com maior proteção ambiental, o qual se coaduna com o artigo $9^{\circ}$, inciso XIII, da Lei ${ }^{\circ}$ 6.938/1981, que traz expressamente a possibilidade de uso de instrumentos econômicos no contexto Política Nacional do Meio Ambiente.

De qualquer forma, este princípio tem efetivo assento no contexto normativo infraconstitucional federal, em dois dispositivos normativos, sem maiores detalhamentos:

a) Explicitamente, no inciso II do artigo $6^{\circ}$ da Lei $\mathrm{n}^{\mathrm{o}} 12.305 / 2010$, mencionando-o em conjunto com o princípio poluidor-pagador;

b) Implicitamente, no artigo 41, inciso I, da Lei $\mathrm{n}^{\circ}$ 12.651/2012, novo Código Florestal, com redação dada pela Lei $n^{\circ}$ 12.727/2012, que trata da possibilidade de instituição de programas de governo com foco no pagamento pelas atividades de conservação e melhoria dos ecossistemas e que gerem serviços ambientais.

Salienta-se que na doutrina especializada ainda são poucos os autores que mencionam expressamente o Princípio do Protetor-Recebedor, dentre eles estão Édis Milaré e Frederico Amado. Segundo Édis Milaré (2015) o objetivo do princípio do Protetor-Recebedor é evitar que o "custo zero" dos serviços e recursos naturais acabe por guiar o sistema de mercado à hiperexploração do meio ambiente. Para exemplificar a efetivação deste princípio no Brasil Milaré refere-se ao caso dos produtores de água do município de Extrema, no sul do Estado de Minas Gerais. A Prefeitura de Extrema influenciada pelo Projeto Produtor de Água, da Agência Nacional de Águas - ANA, instaurou um programa para remunerar os 
proprietários rurais ribeirinhos que empregassem ações para preservar os mananciais da bacia do Rio Jaguari, sub-bacia hidrográfica das Posses, a qual abastecesse o Sistema Cantareira, viabilizando água para a cidade de São Paulo (2015).

Nas palavras de Frederico Amado o mencionado princípio:

Seria a outra face da moeda do princípio do Poluidor-Pagador, ao defender que as pessoas físicas ou jurídicas responsáveis pela preservação ambiental devem ser agraciadas com benefícios de alguma natureza, pois estão colaborando com toda a comunidade para a consecução do direito fundamental ao meio ambiente ecologicamente equilibrado. Assim haverá uma espécie de compensação pelos serviços ambientais. (2012, p. 209).

Ademais, relevante mencionar a perspectiva de Alexandre Altmann, o qual nominou o princípio em questão de "Princípio do Preservador-Recebedor". Dispõe que o sentido o qual conduz este princípio recebe ainda mais atenção quando se considera que muitos provedores de serviços ecossistêmicos têm perdas econômicas devido aos custos de oportunidade e manutenção. Ou seja, frequentemente, quem escolhe preservar deixa de obter ganhos financeiros com o uso da terra para a lavoura ou pastagens, por exemplo. No sistema de pagamento de serviços ambientais, o Princípio do Preservador-Recebedor objetiva equacionar esse desequilíbrio cobrindo, no todo ou em parte, os prejuízos econômicos sofridos pelos provedores de serviços ecossistêmicos.

Nesse contexto, se um possível agente causador de danos ambientais deixasse de se utilizar do recurso natural para fins particulares ou econômicos, com vistas a sua preservação, o mesmo deveria ser reconhecido pelos benefícios prestados à coletividade, mediante o pagamento pela sua opção. Nesta perspectiva, o Princípio do Protetor-Recebedor não operando no contexto de imputações de obrigações de fazer com fim coibir práticas ambientalmente negativas, situar-se-ia no campo do fomento das atitudes que contribuam para a preservação do meio ambiente sadio.

Sua compatibilização com a ordem constitucional envolve, em essência, que se tenha claro que o Protetor-recebedor não pode ser o aquele que tenha, por determinação legal ou judicial, a obrigação de proteção ambiental, pelo menos no ambiente estrito desta obrigação. Nesta perspectiva, $a b$ initio, há que se ter claro que o protetor-recebedor não pode ser o mesmo poluidor-pagador. Não faz nenhum sentido, jurídico nem lógico, que alguém deva receber remuneração para cumprir obrigação da qual já é devedor. Neste sentido anda bem a própria Lei $\mathrm{n}^{\mathrm{o}}$ 12.305/2010 ao trazê-los no mesmo exato inciso.

Todavia, para tudo o que transcenda a obrigação legal de preservação ambiental, há possibilidade de livre fluxo do princípio poluidor-recebedor, como pode ser o caso, v.g., do agricultor que preserve mais do que a reserva legal, ou que ultrapasse os deveres de mera 
abstenção de suprimir vegetação em relação de área de preservação permanente, e assuma uma posição proativa de efetivo monitoramento e manutenção da qualidade ambiental da mesma.

Ademais, em todas as situações onde o protetor-recebedor não seja aquele que teria o dever legal de preservação é evidentemente possível aplicá-lo.

\section{A Legislação Federal sobre o Pagamento por Serviços Ambientais}

Tomar-se-á como referência três normas federais que tratam especificamente da possibilidade do pagamento pelos serviços humanos de favorecimento à manutenção em plenitude dos serviços ambientais.

\subsection{Lei no 12.114/2009: cria o Fundo Nacional sobre Mudança do Clima}

A Lei $n^{\circ} 12.114 / 2009$, regulamentada pelo Decreto Federal $n^{\circ} 7.343 / 2010$, criou o Fundo Nacional sobre Mudança do Clima (FNMC), aborda diferentes tipos de serviços ambientais, como por exemplo: os chamados serviços de regulação, ao prever no artigo $5^{\circ}$, $\S 4^{\circ}$, inciso XI, a possibilidade da aplicação dos recursos do fundo "às atividades de pagamentos por serviços ambientais às comunidades e aos indivíduos cujas atividades comprovadamente contribuam para a estocagem de carbono, atrelada a outros serviços ambientais".

O Fundo Clima tem como objetivo assegurar recursos para projetos, estudos e financiamento de empreendimentos que visem à mitigação e adaptação à mudança do clima e seus efeitos. Assim, referido fundo prevê a concessão de recursos reembolsáveis - que obedecem a critérios de empréstimos do Banco Nacional do Desenvolvimento (BNDES) - e não reembolsáveis -, os quais serão aplicados diretamente pelo Ministério do Meio Ambiente ou na forma das transferências voluntárias previstas na legislação orçamentária, mediante convênios, termos de parceria, acordos, ajustes ou outros instrumentos previstos em lei. No que tange ao público alvo, o Fundo Clima permite uma abrangência mais ampla de 
beneficiários, podendo beneficiar qualquer comunidade ou indivíduo que contribua com o fornecimento dos serviços ambientais abrangidos em sua lei de criação.

O requisito fundamental para obter recursos do Fundo Clima é a apresentação de projetos nos termos das regras estabelecidas pelo BNDES (recursos reembolsáveis) ou pelo Conselho Gestor (recursos não reembolsáveis) ${ }^{4}$.

Infelizmente, a principal fonte de recursos do fundo, antes que a lei completasse um biênio de vida foi redirecionada para outras finalidades ${ }^{5}$.

De qualquer forma, em paralelo, 20 dias após a edição da Lei $\mathrm{n}^{\circ} 12.114 / 2009$, foi editada a Lei $n^{\circ}$ 12.187/2009, que instituiu a Política Nacional de Mudança do Clima (PNMC), que estabelece, entre outras medidas, que o Brasil adotará, como compromisso voluntário nacional, ações de mitigação das emissões de gases de efeito estufa, com vistas a reduzir entre $36,1 \%$ e 38,9\% suas emissões projetadas até 2020. Assim, foi regulamentada tanto a definição de quais serão as projeções de emissões de gases de efeito estufa em 2020, quanto o detalhamento das ações necessárias ao atingimento do compromisso nacional voluntário por meio do Decreto $\mathrm{n}^{\mathrm{o}} 7.390 / 2010$, que projetou o total de emissões do Brasil em 2020 na ordem de 3.236 milhões tonCO2eq.

Embora nem a lei nem o decreto não mencionem expressamente a possibilidade pelo pagamento pelos serviços ambientais de sequestro de carbono, tal se encontra implícito tanto na referência à utilização de instrumentos financeiros e econômicos para promover ações de mitigação e adaptação à mudança do clima, tanto no contexto das diretrizes (Art. $5^{\mathrm{o}}$ VII) como dos instrumentos (Art. $6^{\circ}, \mathrm{X}$ e XI) estabelecidos, destacando-se ainda o Art. $4^{\mathrm{o}}$, IV que estabelece expressamente que a PNMC visará “o fortalecimento das remoções antrópicas por sumidouros de gases de efeito estufa no território nacional”.

De lamentar-se, de qualquer forma, que, no contexto atual, tanto a viabilização de pagamento por serviços ambientais pelo FNMC como a própria implementação da PNMC

\footnotetext{
$4 \mathrm{O}$ artigo $9^{\circ}$, III, do Decreto 7.343/2010, enuncia que o Comitê Gestor do Fundo Clima deverá observar o Plano Nacional sobre Mudança do Clima e a Lei da Política Nacional de Mudança do Clima (Lei no 12.187/2009) para estabelecer diretrizes para a aplicação de recursos do respectivo fundo.

5 Os recursos destinados ao FNMC contemplam, além de dotações orçamentárias da União, doações ou empréstimos de instituições internacionais. Todavia, os principais recursos $(60 \%)$ proviriam dos recursos de que tratava o inciso II do $\S 2^{\circ}$ do art. 50 da Lei 9.478, de 6/8/1997, que diziam respeito à parcela de recursos devida pelos concessionários de exploração de petróleo em áreas de grande porte definidas nos termos da referida lei ao governo federal à título de participação especial governamental, incidente sobre a receita bruta da produção, deduzidos os royalties, os investimentos na exploração, os custos operacionais, a depreciação e os tributos previstos na legislação em vigor, da qual $10 \%$ seria destinado a Ministério do Meio Ambiente. Posteriormente, a Lei $\mathrm{n}^{\circ}$ 12.734, de 30/11/2012 simplesmente excluiu o FNMC dentre os benefíciários destes valores, maior fonte e efetivamente única receita corrente destinada ao mesmo.
}

Revista de Direito Ambiental e Socioambientalismo | e-ISSN: 2525-9628 | Brasília | v. 3 | n. 1 | p. 18 - 39 | Jan/Jun. 2017. 
dependam ainda de políticas públicas atreladas a um contexto orçamentário absolutamente limitado.

\subsection{Lei no 12.512/2011: institui o Programa de Apoio à Conservação Ambiental Bolsa Verde}

O Programa de Apoio à Conservação Ambiental, denominado Bolsa Verde, foi instituído pela Lei Federal $\mathrm{n}^{\mathrm{o}} 12.512 / 2011$, com regulamentação dada pelo Decreto $\mathrm{n}^{\circ}$ 7.572/2011, abrangendo a possibilidade de pagamento pelos serviços que visam à manutenção da cobertura vegetal da propriedade onde a família beneficiária está inserida, bem como o uso sustentável dos seus recursos naturais.

Embora não seja utilizada a expressão serviços ambientais, trata-se de fomento específico relacionado aos serviços ambientais de provisão (produtos obtidos dos ecossistemas, como alimentos, água, combustível).

O referido programa foi criado a fim de apoiar famílias em situação de extrema pobreza que desenvolvem atividades de conservação ambiental. O programa possui gestão pública e compartilhada entre o Comitê Gestor, Ministério do Meio Ambiente, gestores locais e a Caixa Econômica Federal.

Os provedores dos serviços ambientais do Programa Bolsa Verde poderão ser somente produtores rurais familiares, comunidades tradicionais e assentados de reforma agrária. Nos termos do artigo $5^{\circ}$ do Decreto Federal n $7.572 / 2011$ :

Art. $5^{\circ}$ Poderão ser beneficiárias do Programa Bolsa Verde as famílias em situação
de extrema pobreza que desenvolvam atividades de conservação ambiental nas
seguintes áreas:
I - Florestas Nacionais, Reservas Extrativistas Federais e Reservas de
Desenvolvimento Sustentável Federais;
II - Projetos de Assentamento Florestal, Projetos de Desenvolvimento Sustentável ou
Projetos de Assentamento Agroextrativista instituídos pelo Instituto Nacional de
Colonização e Reforma Agrária - INCRA; e
III - outras áreas rurais indicadas pelo Comitê Gestor do Programa Bolsa Verde e
definidas pelo Ministério do Meio Ambiente.

No que tange a fonte de recursos do Programa Bolsa Verde, a única fonte de financiamento é o orçamento da União, nos termos do artigo 28 da Lei no 12.512/2011. Segundo o artigo $7^{\circ}$ do Decreto $\mathrm{n}^{\circ} 7.572 / 2011$, as famílias interessadas para serem beneficiadas com os recursos do Programa em questão precisam preencher dois requisitos:

1. Estar inscrita no cadastro a ser mantido pelo Ministério do Meio Ambiente contendo informações sobre as atividades de conservação; 
2. Aderir ao Programa Bolsa Verde por meio de assinatura do termo de adesão, no qual serão especificadas as atividades de conservação a serem desenvolvidas.

Um avanço do Programa Bolsa Verde em relação ao Fundo Clima, é a previsão de monitoramento da cobertura vegetal das áreas abrangidas, com frequência mínima anual e sob responsabilidade do órgão competente; verificação in loco por critérios de amostragem e o Comitê Gestor pode também estabelecer critérios adicionais de monitoramento (Art. 19 do Decreto Federal no 7.572/2011).

\subsection{Lei no 12.651/2012: institui o novo Código Florestal}

A Lei $n^{\circ}$ 12.651/2012 intitulada como o Novo Código Florestal, coma redação dada pela lei 12.727/2012, prevê em seu artigo 41, inciso I, a possibilidade expressa de remuneração por serviços ambientais de forma ampla e abrangente em nível de todo o território nacional. In verbis, com grifos nossos:

Art. 41. É o Poder Executivo federal autorizado a instituir, sem prejuízo do cumprimento da legislação ambiental, programa de apoio e incentivo à conservação do meio ambiente, bem como para adoção de tecnologias e boas práticas que conciliem a produtividade agropecuária e florestal, com redução dos impactos ambientais, como forma de promoção do desenvolvimento ecologicamente sustentável, observados sempre os critérios de progressividade, abrangendo as seguintes categorias e linhas de ação:

I - pagamento ou incentivo a serviços ambientais como retribuição, monetária ou não, às atividades de conservação e melhoria dos ecossistemas e que gerem serviços ambientais, tais como, isolada ou cumulativamente:

a) o sequestro, a conservação, a manutenção e o aumento do estoque e a diminuição do fluxo de carbono;

b) a conservação da beleza cênica natural;

c) a conservação da biodiversidade;

d) a conservação das águas e dos serviços hídricos;

e) a regulação do clima;

f) a valorização cultural e do conhecimento tradicional ecossistêmico;

g) a conservação e o melhoramento do solo;

h) a manutenção de Áreas de Preservação Permanente, de Reserva Legal e de uso restrito; [...]

Verifica-se que o inciso I elenca uma classificação de serviços ambientais essencialmente nos mesmos moldes da Avaliação Ecossistêmica do Milênio. Como demonstrado supra tais serviços são essenciais para a manutenção da vida na Terra. Neste contexto, os incentivos à preservação dos serviços ambientais devem ser pensados como um meio de envolver os moradores de regiões ricas em recursos naturais no controle dos mesmos, os quais receberão um benefício por desempenharem um serviço de conscientização e fiscalização da manutenção dos serviços ambientais. 
Além do específico pagamento por serviços ambientais, os incisos II e III do mesmo artigo da lei apresentam algumas possibilidades de pagamento indireto por serviços ambientais, por meio de compensações fiscais e econômicas. In verbis, com grifos nossos:

II - compensação pelas medidas de conservação ambiental necessárias para o cumprimento dos objetivos desta Lei, utilizando-se dos seguintes instrumentos, dentre outros:

a) obtenção de crédito agrícola, em todas as suas modalidades, com taxas de juros menores, bem como limites e prazos maiores que os praticados no mercado;

b) contratação do seguro agrícola em condições melhores que as praticadas no mercado;

c) dedução das Áreas de Preservação Permanente, de Reserva Legal e de uso restrito da base de cálculo do Imposto sobre a Propriedade Territorial Rural - ITR, gerando créditos tributários;

d) destinação de parte dos recursos arrecadados com a cobrança pelo uso da água, na forma da Lei $\mathrm{n}^{\circ}$ 9.433, de 8 de janeiro de 1997, para a manutenção, recuperação ou recomposição das Áreas de Preservação Permanente, de Reserva Legal e de uso restrito na bacia de geração da receita;

e) linhas de financiamento para atender iniciativas de preservação voluntária de vegetação nativa, proteção de espécies da flora nativa ameaçadas de extinção, manejo florestal e agroflorestal sustentável realizados na propriedade ou posse rural, ou recuperação de áreas degradadas;

f) isenção de impostos para os principais insumos e equipamentos, tais como: fios de arame, postes de madeira tratada, bombas d'água, trado de perfuração de solo, dentre outros utilizados para os processos de recuperação e manutenção das Áreas de Preservação Permanente, de Reserva Legal e de uso restrito;

III - incentivos para comercialização, inovação e aceleração das ações de recuperação, conservação e uso sustentável das florestas e demais formas de vegetação nativa, tais como:

a) participação preferencial nos programas de apoio à comercialização da produção agrícola;

b) destinação de recursos para a pesquisa científica e tecnológica e a extensão rural relacionadas à melhoria da qualidade ambiental.

Embora a própria norma em comento como um todo mereça ser objeto de crítica, especialmente pela conivência com degradações consolidadas, o que se reflete também na própria regulamentação do pagamento por serviços ambientais, há que se louvar o fato de que se trata da primeira norma federal nacional que efetivamente procura detalhar o pagamento por serviços ambientais de forma mais ampla, permitindo que se vislumbre, inclusive, que este pagamento pode operar tanto de forma direta (inciso I) como de forma indireta (incisos I a III), neste caso sem que haja necessário desembolso de dinheiro por parte do Poder Público.

\subsection{Considerações sobre a compatibilidade da legislação federal sobre os serviços ambientais com os cânones constitucionais e principiológicos aplicáveis}

Há que se ter claro que todas as normas examinadas operam na dependência de editais específicos ou outros atos administrativos sem maiores delimitações legais. Neste 
sentido, revela-se impossível, a priori, apenas com o texto da lei, verificar se o pagamento pelos serviços ambientais operaria dentro dos cânones constitucionais supra estabelecidos, no sentido de configurarem-se em pagamentos (diretos ou indiretos) apenas por atividades que transcendam ao mero dever legal de preservação.

Outrossim, é preciso ter claro que se trata, em todos os casos, de normas efetivamente limitadas, especialmente em relação ao detalhamento das hipóteses específicas de pagamento e seu próprio financiamento, que se dá sem a existência de fontes financeiras regulares, de sorte que a eficácia das próprias normas fica também condicionada à efetiva disponibilidade orçamentária para os programas, a cada ano, na respectiva lei orçamentária.

Neste sentido, melhor seria que houvesse uma lei específica, trançando diretrizes para uma Política Nacional de Pagamento por Serviços Ambientais, conforme as peculiaridades que o assunto abrange, especialmente tendo-se em conta que a ausência de uma legislação autônoma sobre serviços ambientais não só compromete a efetividade deste tipo de política como a também própria garantia de que o pagamento pelos serviços ambientais opere dentro dos cânones constitucionais aqui estabelecidos, como pagamentos (diretos ou indiretos) por serviços humanos de auxílio ao pleno desenvolvimento de serviços ambientais que transcendam ao mero dever legal de preservação a que estão sujeitos os envolvidos ${ }^{6}$.

\section{Conclusão}

6 Sobre o tema há basicamente dois grandes projetos de lei em tramitação, ambos buscando instituir uma Política Nacional de Pagamento por Serviços Ambientais (PNPSA): na Câmara dos Deputados o Projeto de Lei ${ }^{\circ}$ 792/2007 e no Senado Federal o Projeto de Lei no 276/2013. Na mesma linha do Projeto de Lei no 276/2013, o Projeto de Lei n $^{\circ} 792 / 2007$ distingue "serviços ecossistêmicos" de "serviços ambientais", nos termos que seguem "Art. $2^{\circ}$ Para os fins desta Lei, consideram-se: I - ecossistemas: unidades espacialmente delimitadas, caracterizadas pela especificidade das inter-relações entre os fatores bióticos e abióticos; II - serviços ecossistêmicos: benefícios relevantes para a sociedade gerados pelos ecossistemas, em termos de manutenção, recuperação ou melhoria das condições ambientais, nas seguintes modalidades: a) serviços de provisão: os que fornecem bens ou produtos ambientais utilizados pelo ser humano para consumo ou comercialização, tais como água, alimentos, madeira, fibras e extratos, entre outros; b) serviços de suporte: os que mantêm a perenidade da vida na Terra, tais como a ciclagem de nutrientes, a decomposição de resíduos, a produção, a manutenção ou a renovação da fertilidade do solo, a polinização, a dispersão de sementes, o controle de populações de potenciais pragas e de vetores potenciais de doenças humanas, a proteção contra a radiação solar ultravioleta e a manutenção da biodiversidade e do patrimônio genético; c) serviços de regulação: os que concorrem para a manutenção da estabilidade dos processos ecossistêmicos, tais como o sequestro de carbono, a purificação do ar, a moderação de eventos climáticos extremos, a manutenção do equilíbrio do ciclo hidrológico, a minimização de enchentes e secas e o controle dos processos críticos de erosão e de deslizamento de encostas; e d) serviços culturais: os que proveem à sociedade humana benefícios recreacionais, estéticos, espirituais e outros não materiais; III - serviços ambientais: atividades individuais ou coletivas que favorecem a manutenção, recuperação ou melhoria dos serviços ecossistêmicos." (grifamos). Ambos os Projetos definem conceitos, objetivos e diretrizes de uma Política Nacional de Pagamento por Serviços Ambientais. Há que se ter claro, neste caso, que, em que pese os avanços técnicos em termos de detalhamento, ambos os projetos não explicitam, todavia que o pagamento dos serviços ambientais operará nos cânones constitucionais aqui fixados.

Revista de Direito Ambiental e Socioambientalismo | e-ISSN: 2525-9628 | Brasília | v. 3 | n. 1 | p. 18 - 39 | Jan/Jun. 2017. 
A presente pesquisa teve por foco responder a seguinte indagação: a legislação federal brasileira apresenta condições para viabilizar o adequado pagamento por serviços ambientais, em conformidade com os ditames constitucionais e principiológicos sobre o tema?

Neste sentido, iniciou-se o trabalho com a delimitação do conceito de serviços ambientais, entre os quais se incluem, entre outros, a regulação do clima na Terra, a manutenção da qualidade do ar, a formação dos solos, o armazenamento de carbono, a preservação dos recursos hídricos e da biodiversidade, dos quais o bem-estar da humanidade depende inexoravelmente. Em relação aos mesmos, concluiu-se que abrangem atividades, produtos e processos essenciais que a natureza fornece e que possibilitam a manutenção da vida como um todo, especialmente a vida humana, constatando-se também que a colaboração humana na preservação ou restauração ambiental pode revelar-se eventualmente facilitadora para o desenvolvimento e manutenção desses serviços. Outrossim, em termos conceituais, pontuou-se que o pagamento por serviços ambientais envolve, na verdade, o pagamento por serviços humanos de facilitação da manutenção ou desenvolvimento de serviços ambientais, os quais, em essência, abrangem serviços prestados basicamente pela natureza.

Fixado este conceito, o segundo tópico sintetizou a investigação sobre as bases normativas que devem servir de norte para a temática deste pagamento pelos serviços ambientais, com foco especial na Constituição e nos princípios atinentes à matéria, com vistas a construir um conceito normativo apto a medir a efetiva adequação dos modelos de pagamento por serviços ambientais à ordem constitucional. Neste sentido se concluiu que só se considera adequado à ordem constitucional o pagamento por serviços ambientais o pagamento por apenas por atividades humanas que transcendam ao mero dever legal de preservação ambiental.

Estabelecida esta referência de análise, no terceiro tópico foi apresentada uma análise reflexiva da legislação federal vigente no Brasil sobre os serviços ambientais, tendo por foco, na sequência, a análise das três normas federais vigentes sobre o tema: a Lei no 12.114/2009, que cria o Fundo Nacional sobre Mudança de Clima; a Lei ${ }^{\circ} 12.512 / 2011$ que cria o Programa Bolsa Verde e a Lei no 12.651/2012, que institui o novo Código Florestal às quais se seguiram considerações pontuais sobre o enquadramento dessas normas nos cânones constitucionais fixados no tópico anterior. Neste compasso, concluiu-se que a legislação 
federal infra-constitucional sobre o tema é escassa, tanto tendo em vista a qualidade como a quantidade de dispositivos. Igualmente, constatou-se que todas as normas examinadas operam na dependência de editais específicos ou outros atos administrativos sem maiores delimitações legais, o que compromete inclusive que se possa afirmar, a priori, que as hipóteses legais de pagamento pelos serviços ambientais operem dentro dos cânones constitucionais antes fixados, observando-se também tratar-se de normas efetivamente limitadas, especialmente em relação ao detalhamento das hipóteses específicas de pagamento e seu próprio financiamento, o qual não conta com fontes financeiras regulares - como poderia ser a vinculação a um tributo específico - de sorte que a eficácia das normas vigentes resta também condicionada pela disponibilidade de orçamento, ano a ano.

Ponderou-se, por derradeiro, a necessidade de lei específica, traçando diretrizes para uma Política Nacional de Pagamento por Serviços Ambientais, tendo-se presente que justamente pela a ausência de uma legislação autônoma sobre serviços ambientais é que se vê comprometida tanto a efetividade deste tipo de política como também a própria garantia de que o pagamento pelos serviços ambientais opere dentro dos cânones constitucionais ora fixados, como pagamentos (diretos ou indiretos) por serviços humanos de auxílio ao pleno desenvolvimento de serviços ambientais que transcendam ao mero dever legal de preservação a que estão sujeitos os envolvidos.

\section{Referências Bibliográficas}

AHRENS, Caroline; AHRENS, Sergio Ahrens. Previsão Normativa para o pagamento por serviços ambientais no código florestal brasileiro. In: Serviços ambientais em sistemas agrícolas e florestais do Bioma Mata Atlântica. PARRON, Lucilia Maria et al., (editores técnicos). Brasília: $\quad$ Embrapa, 2015. Disponível em: https://ainfo.cnptia.embrapa.br/digital/bitstream/item/131969/1/Livro-Servicos-AmbientaisEmbrapa.pdf. Acesso em: 02 de maio de 2017. 
Avaliação. Resumo: Um relatório do Grupo de Trabalho da Estrutura Conceptual da Avaliação do Milênio dos Ecossistemas, 2003. Millenium Ecosystem Assessment. Disponível em: 〈http://www.millenniumassessment.org/documents/document.63.aspx.pdf >. Acesso em: 03 de maio de 2017.

ALTMANN, Alexandre. Princípio do Preservador-Recebedor: contribuições para a consolidação de um novo princípio de Direito Ambiental a partir do sistema de pagamento por serviços ambientais. Disponível em: <http://www.planetaverde.org/arquivos/biblioteca/arquivo_20131207160003_4833.pdf. $>$.

Acesso em: 02 de maio de 2017.

AMADO, Frederico. Direito Ambiental Esquematizado. Rio de Janeiro: Método, 2012.

ANTUNES, Paulo de Bessa. Direito Ambiental. 16. ed. São Paulo: Atlas, 2014.

BRASIL.Câmara dos Deputados. Projeto de Lei $\mathbf{n}^{\mathbf{0}}$ 792/2007: Institui a Política Nacional de Pagamento por Serviços Ambientais (PNPSA). Disponível em: <http://www.camara.gov.br/proposicoesWeb/prop_mostrarintegra;jsessionid=0DC9C4FAB84 B53EDCF245E7F14427B3C.proposicoesWebExterno2?codteor=1402304\&filename=Tramita cao-PL+792/2007>. Acesso em: 02 de maio de 2017.

BIRNFELD, Carlos André. O princípio poluidor-pagador e suas potencialidades: uma leitura não economicista da ordem constitucional brasileira. Tese (Doutorado em Direito) - Universidade Federal de Santa Catarina, 2003.

BIRNFELD, Carlos André. Cidadania Ecológica. Pelotas: Delfos, 2006.

BUTZKE, Alindo. Fundamentos ecológicos dos serviços ambientais. Direito e economia verde: natureza jurídica e aplicações práticas do pagamento por serviços ambientais, como instrumento de ocupações sustentáveis. Adir Ubaldo Rech (org.). Caxias do Sul: Educs, 2011.

CORDEIRO, Renato Caporali. Da Riqueza das Nações à Ciência das Riquezas. São Paulo: Loyola, 1995.

FAO (Food and Agriculture Organization of The United Nations). FAO: Incentivos gera redução de desmatamento no Brasil. Disponível em <http://www.fao.org/brasil/noticias/detail-events/pt/c/426091/>. Acesso em: 03 de maio de 2017.

FIORILlO, Celso Antônio Pacheco. Curso de direito ambiental brasileiro. 14. ed. rev., ampl. e atual. em face da Rio+20 e do Novo "Código" Florestal. São Paulo: Saraiva, 2013.

GRANZIERA, Maria Luiza Machado. Direito Ambiental. São Paulo: Atlas, 2009.

MACHADO, Paulo Affonso Leme. Direito Ambiental Brasileiro. 20. ed. rev., atual. e ampl. São Paulo: Malheiros, 2012.

MATTOS, Luciano Mansor de. Base teórica e pontos fundamentais para a concepção de políticas públicas de serviços ambientais. In: Serviços ambientais em sistemas agrícolas e florestais do Bioma Mata Atlântica. PARRON, Lucilia Maria et al., (editores técnicos). Brasília: $\quad$ Embrapa, 2015. Disponível em: https://ainfo.cnptia.embrapa.br/digital/bitstream/item/131969/1/Livro-Servicos-AmbientaisEmbrapa.pdf. Acesso em: 02 de maio de 2017. 
MILARÉ, Édis. Direito do Ambiente. 10. ed. rev., atual. e ampl. São Paulo: Revista dos Tribunais, 2015.

NETO, Fernando Cesar de Veiga; MAY, Peter H. Mercados para serviços ambientais. In: Economia do meio ambiente: teoria e prática. Peter H. May (org.). 2. ed. Rio de Janeiro: Elsevier, 2010.

NOVION, Henry Phillippe Ibanes de. O que são serviços ambientais? Disponível em: $<$ https://uc.socioambiental.org/servicos-ambientais/o-que-sao-servicos-ambientais $>$. Acesso em: 29 de abril de 2017.

ORTIZ, Ramon Arigoni; TITO, Marcos Rügnitz. Pagamento por serviços ambientais: desafios para estimular a demanda empresarial. Disponível em: $<$ http://sectordialogues.org/sites/default/files/mmaa - publicacao - 5 convocatoria _portugues.pdf $>$. Acesso em: 30 de abril de 2017.

PEREIRA, Lígia; TITO, Marcos Rügnitz; BONER, Jan. Pagamentos por serviços ambientais: perspectivas para a Amazônia Legal. WUNDER, Sven Wunder (coord.). 2. ed., rev., Brasília: $\quad 2009 . \quad$ Disponível em: 〈http://www.mma.gov.br/estruturas/168/_publicacao/168_publicacao17062009123349.pdf $>$. Acesso em: 30 de abril de 2017.

SANTOS, Priscilla; et al. Marco regulatório sobre pagamento por serviços ambientais no Brasil. Belém: IMAZON/ FGV, 2012. Disponível em:< https://documentacao.socioambiental.org/noticias/anexo noticia//22354 20120705 110954.p df>. Acesso em: 29 de abril de 2017.

SEEHUSEN, Susan Edda; PREM Ingrid. Por que Pagamentos por Serviços Ambientais? In: Pagamentos por Serviços Ambientais na Mata Atlânica: lições aprendidas e desafios/ Fátima Becker Guedes e Susan Edda Seehusen (Organizadoras). 2.ed. rev. Brasília: MMA, $2012 . \quad$ Disponível em: <http://www.ciliosdoribeira.org.br/sites/default/files/arquivos/pagamentos_por_servicos_ambi entais na mata atlantica 2edicao revisada.pdf> Acesso em: 30 de abril de 2017. 